\section{NOTICE \\ PORTIONS OF THIS REPORT ARE ILLEGIBLE It has been reproduced from the bost availahie couy to permit the breadest enssible avail. stilitr.}

LA-10009-M

Manual

(ISPO-203)

UC-15

Issued: March 1984

\title{
Plutonium Nitrate Bottle Counter Manual
}

$2 A--10009-1 i$

DE8 $\$ 11020$

H. O. Menlove

E. L. Adams

O. R. Holbrooks

\section{DISCLAIMER}

This report was prepared as an account of work sponsored by an agency of the United States Government. Neither the United States Government nor any agency thereof, nor any of their employees, makes any warranty, express or implied, or assumes any legal liability or responsibility for the accuracy, completeness, or usefulness of any information, apparatus, product, or process disclosed, or represents that its use would not infringe privately owned rights. Reference herein to any specific commercial product, process, or service by trade name, trademark, mariufacturer, or otherwise does not necessarily constitute or imply its endorsement, recommendation, or favoring by the United States Government or any agency thereof. The views and opinions of authors expressed herein do not necessarily state or reflect those of the United States Government or any agency thereof.

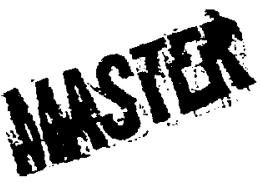




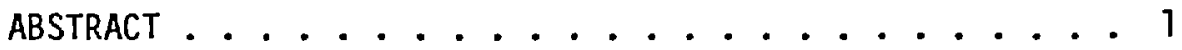

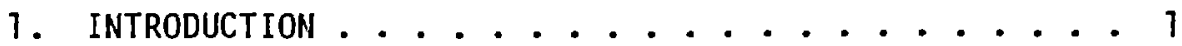

2. MECHANICAL COMPONENTS ............ 2

2.1. Detector Body ............ 2

2.2. Detector Cart ........... 3

2.3. Calibration Source ........... 3

3. ELECTRICAL COMPONENTS ............ 4

3.1. Detector Tubes ............ 4

3.2. Electronics ............ 4

4. OPERATING CHARACTERISTICS ......... 4

4.1. Efficiency ............ 4

4.2. Detector Neutron Die-Away Time ....... 4

4.3. Detector Deadtime .......... 5

4.4. Axial and Radial Response Profiles...... 6

5. OPERATING PROCEDURES AND CALIBRATION ....... 6

5.1. Initial Check-0ut . . . . . . . . 6

5.2. Solution Calibration ......... 7

5.2.1. Scan Profile........... 9

5.2.2. Calibration Data .........99

5.2.3. Multiplication Correction ..... 13

5.2.4. Californium Normalization ...... 16

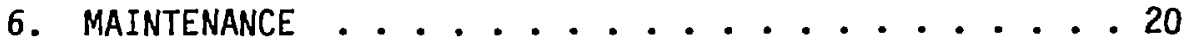

6.1. Detector Body ............ 20

6.2. Amplifier Test Procedures ......... 21

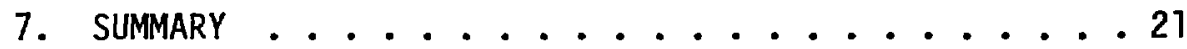

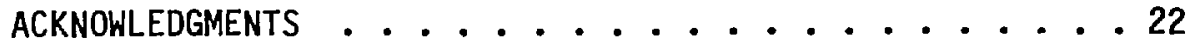

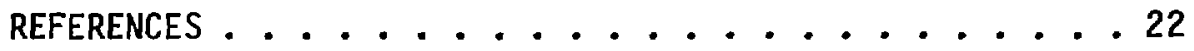


PLUTONIUM NITRATE BOTTLE COUNTER MANUAL

by

H. O. Menlove, E. L. Adams, and 0. R. Holbrooks

\begin{abstract}
A neutron coincidence counter has been designed for plutonium nitrate assay in large storage bottles. This assay system can be used in the reprocessing plant or in the nitrate-to-oxide conversion facility. The system is based on the family of neutron detectors similar to the high-level neutron coincidence counter. This manual describes the system and gives performance and calibration parameters for typical applications.
\end{abstract}

1. INTRODUCTION

Analysis of plutonium nitrate samples by International Atomic Energy Agency (IAEA) inspectors has been made increasingly difficult by transportation regulations. To reduce shipping requirements and to obtain more timely results, independent on-site verification capability is needed, particularly for reprocessing plants and plutonium facilities.

We have developed a system for quantitative verification of the amount of plutonium in large product cylinders. The system is portable and the samples can be assayed in the bottles normally used to store and transfer samples. Fuel rods can also be assayed in the detector.

This unit resembles the high-level neutron coincidence counter ${ }^{1}$ (HLNCC) in that it uses the same electronics ${ }^{2}$ and counts the coincidence neutrons from the spontaneous fission of the ${ }^{240} \mathrm{Pu}$-effective mass. However, it is designed to operate for much taller samples $(21.0 \mathrm{~m})$ than is the HLNCC. 
This manual describes the components, performance characteristics, and operating and calibration procedures for the plutonium nitrate bottle counter (PLBC).

\section{MECHANICAL COMPONENTS}

\subsection{Detector Body}

Figure $i$ is a schematic of the PLBC showing a cross section of the detector body. The sample cavity accommodates samples that fit in the 14.4-cm-diam through-hoie. A thin layer of cadmium $(0.4 \mathrm{~mm})$ lines the sample cavity to prevent thermal neutrons from reflecting into the nitrate sample. This cadmium is covered with 0.8-mm-thick aluminum to provide mechanical protection to the cadmium. On the outside of the polyethylene body, a 0.4 -mm-thick cadmium liner absorbs low-energy, room-background neutrons. Figure 2 shows the detector head.

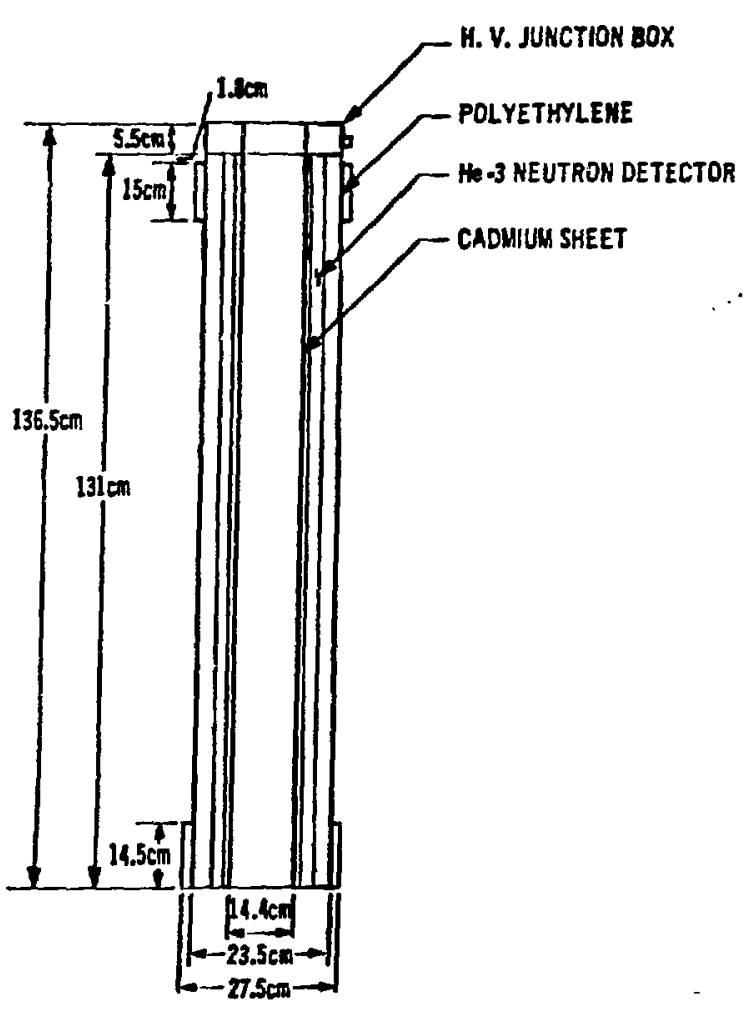

Fig. 1. Schematic diagram of PLBC.

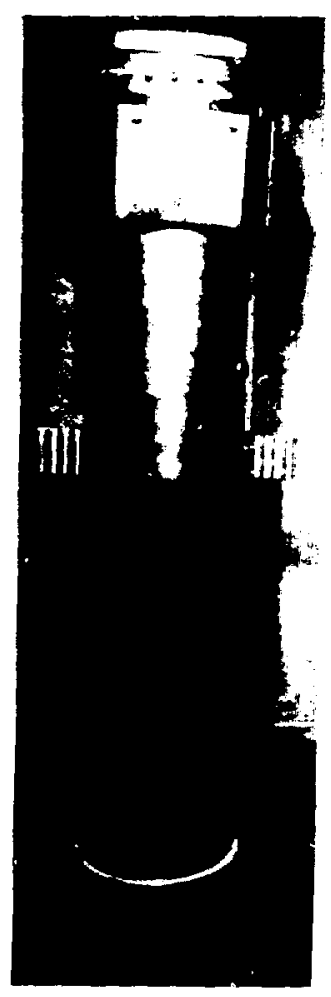

Fig. 2. PLBC detector head. 


\subsection{Detector Cart}

The detector support cart shown in Fig. 3 is designed so that the plutonium nitrate sampies can be lowered through the top of the counter using an overhead crane or fork lift. The cart has wheels so that it can be rolled into the measurement position. The shelf on the cart shown in Fig. 4 is used to support the electronic components.

\subsection{Calibration Source}

The PLBC is normally equipped with a ${ }^{252}$ Cf calibration normalization source. A source with an initial intensity of $20.02 \mu \mathrm{g}$ is adequate for at least 5 years of use in the PLBC. The initial source used with the PLBC unit supplied to the IAEA is ${ }^{252} \mathrm{Cf}$ source number $C R-5$, wlich had a yierd of $7.93 \times 10^{4} \mathrm{n} / \mathrm{s}$ on November $17,1983$.

The 12-mm-diam by 386-mm-1ong aluminum rod supplied with the system is used to insert the californium source into the top of the PLBC. This source is used to check the system operation and normalize the calibration curve in the same manner as for the HLNCC.

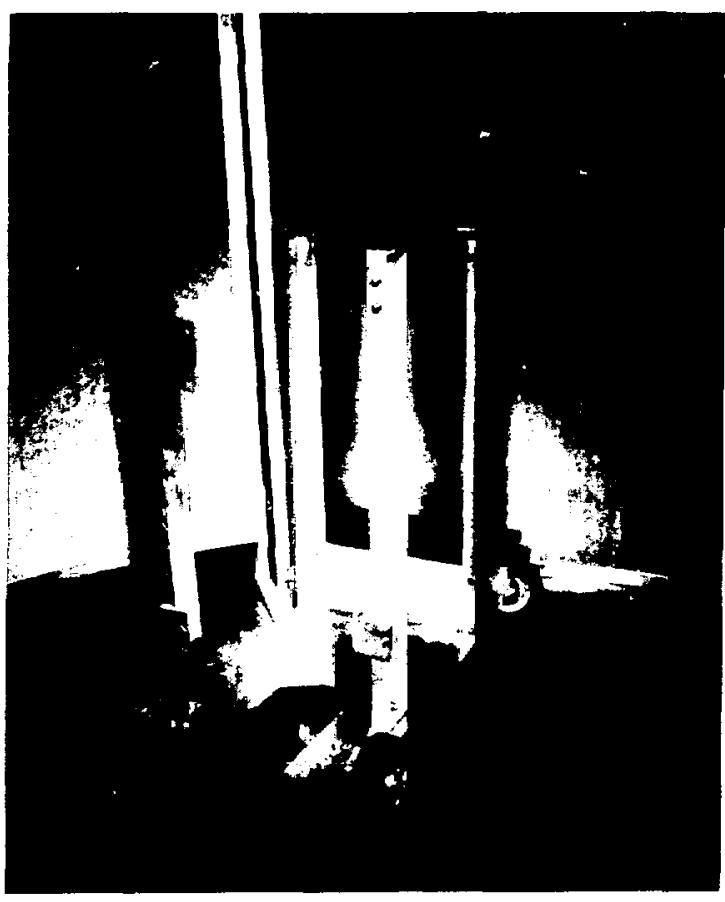

Fig. 3. Partially assembled PLBC support cart.

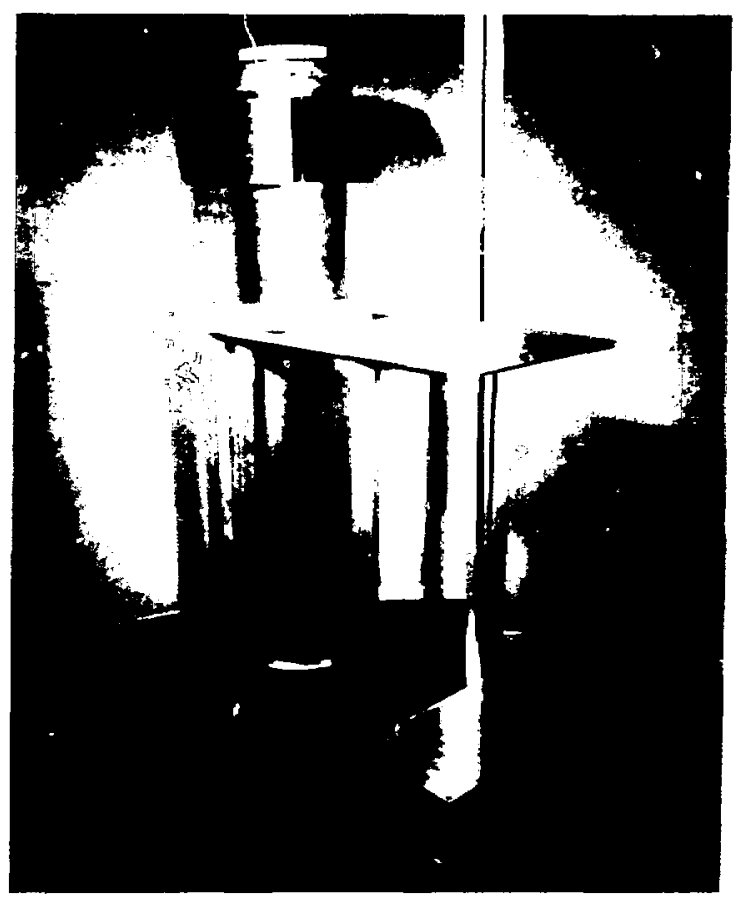

Fig. 4. PLBC cart' plus detector head. 
3.1. Detector Tubes

DESCRIPTION OF $3_{\text {He TUBES }}$

The PLBC contains twelve ${ }^{3}$ He tubes with characteristics as listed in Table I. The tubes have been matched to operate at the same electronic settings as for the HLNCC.

\subsection{Electronics}

The electronics package* for the

Tube model

Active length

Diameter

Fill pressure

Gas quench

Cladding

Operating high voltage $1500 \mathrm{~V}$
RS-P4-0848-203

$121.9 \mathrm{~cm}$

$2.5 \mathrm{~cm}$

4 atm

$\mathrm{Ar}+\mathrm{CH}_{4}$

Stainless stee 1

PLBC is the same as that used for the

HLNCC. The complete PLBC system including the detector head, shift-register electronics, ${ }^{2}$ and Hewlett-Packard HP-97 calculator is shown in Fig. 5 . The normal settings for the electronics follow.

Discriminator level $=3.0(1.5 \mathrm{~V})$

High voltage

$=7.5(1500 \mathrm{~V})$

Gate

$=64 \mu \mathrm{s}$

Time

= Desired run time (200-s recycle)

\section{OPERATING CHARACTERISTICS}

\subsection{Efficiency}

The detector was designed to be undermoderated, that is, to have less polyethylene wall tinickness than would be the case for maximum counting efficiency. This was because of the high hydrogen content in the plutonium nitrate bottles and the desire to keep the counter weight low. The efficiency for a ${ }^{252} \mathrm{Cf}$ neutron source in an empty counter is $8.4 \%$.

\subsection{Detector Neutron Die-Away Time}

The proper gate setting in a neutron coincidence counter depends on the neutron die-away time $(\tau)$ in the system. For minimum error, the coincidence

*IRT Corporation, San Diego, Califoria; HEC-100 SR electronics package. 


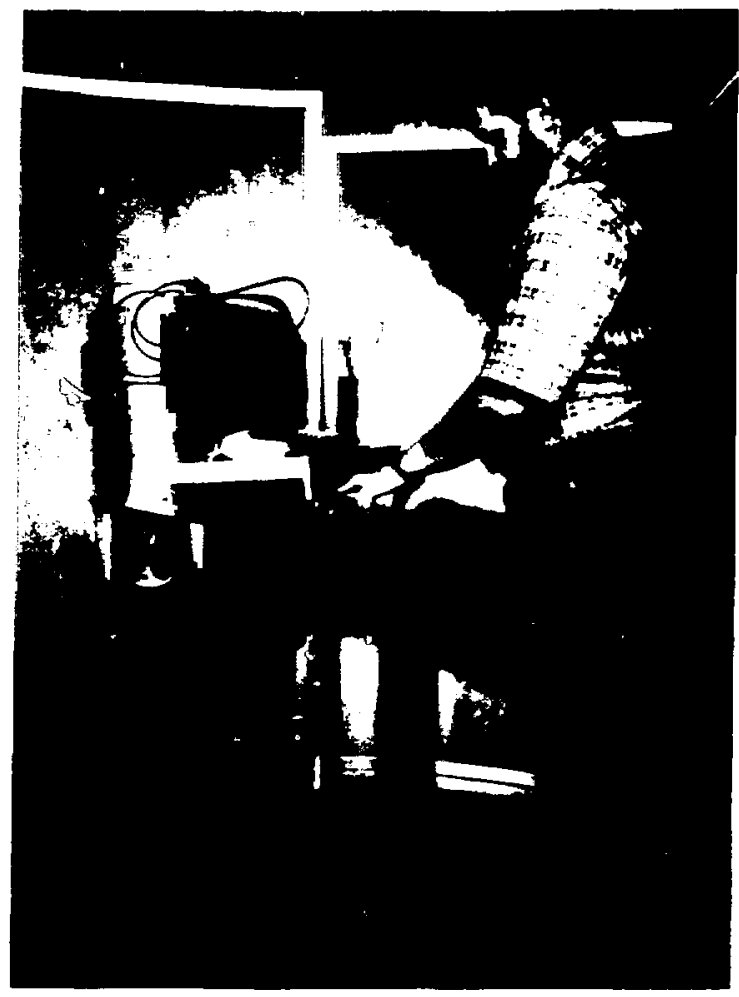

Fig. 5. Complete PLBC system including detector, support cart, HEC-100 shift-register electronics, and HP-97 calculator.

gate length should be set equal to $21.2 \tau$. A ${ }^{252} \mathrm{Cf}$ source was used to measure the die-away time. The neutron die-away time is $27.7 \mu \mathrm{s}$. We are using a gate setting of $64 \mu \mathrm{s}$, rather than $32 \mu \mathrm{s}$, to obtain a more unifom axial efficiency profile as described in Sec. 4.4.

\subsection{Detector Deadtime}

The PLBC uses the same basic electronics and preamplifiers (six channels) as does the HLNCC. Because of this, we use the same deadtime coefficient as for the HLNCC,

$$
\delta(T)=\left(2.30+1.62 \times 10^{-6}\right) \mu s \text { or } \delta \simeq 2.4 \mu \mathrm{s},
$$

where $T$ is the totals rate in counts/second. 
The corrected counting rates are

$T($ corr. $)=T e^{\delta T / 4}$

and

$$
R(\text { corr. })=R e^{\delta T}
$$

It is important to use the same deadtime coefficient for both calibration and assay.

\subsection{Axial and Radial Response Profiles}

To determine sample geometry effects, we positioned a ${ }^{252} \mathrm{Cf}$ neutron point source at various locations in the sample cavity. Both totals and coincidence rates were measured at each location, and the results of the measurements are shown in Fig. 6. The normalized totals rates are shown by the top curve and the coincidence response by the bottom curve in Fig. 6 . The slight bumps at each end $(15$ and $115 \mathrm{~cm})$ are to compensate for less moderation at the ends of the plutonium nitrate sample. The extended, flat efficiency zone of $2105 \mathrm{~cm}$ was obtained in the detector design by placing polyethylene rings at each end of the counter to increase the efficilency and compensate for neutron leakage. The detector moderator configuration is shown in Fig. 1 .

\section{OPERATING PROCEDURES AND CALIBRATION}

\subsection{Initial Check-Out}

The initial check-out and operating procedures are the same as for the HLNCC. Use the following procedure:

(1) Connect the HEC-100 to the HP-97 and the PLBC.

(2) Check the HEC-100 for proper line voltage (110 or $240 \mathrm{~V})$ and set controls as listed in Sec. 3.2. 


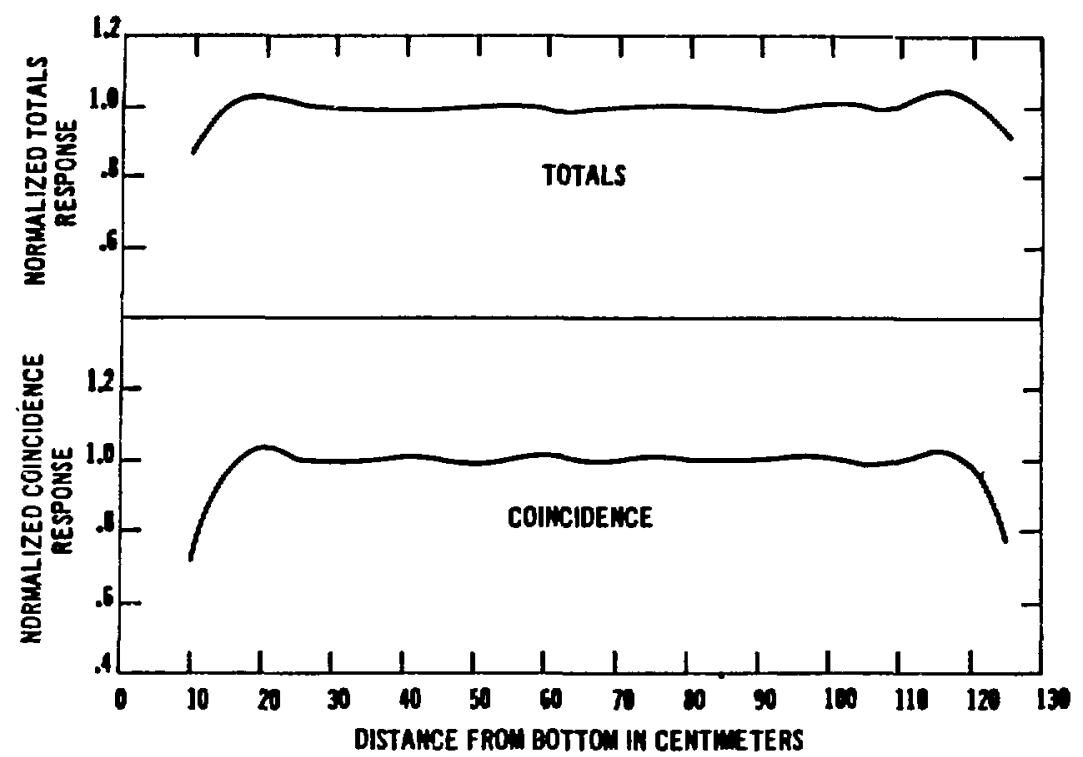

Fig. 6. Normalized totals and coincidence counting rates

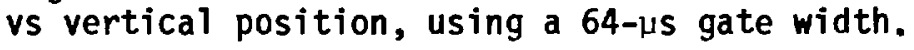

(3) Measure room background (100s) and observe that there are no net coincidence counts above normal statistical fluctuations and that the totals rate is below 2500 counts $/ \mathrm{s}$, depending on the amount of plutonium stored near the measurement position.

(4) Place the ${ }^{252} \mathrm{Cf}$ calibration source attached to the source holder in the top of the PLBC and take several 100-s counts. If the counting rate (after decay corrections) is within a few per cent of the expected value from the calibration measurement, then proceed with assay and normalize the calibration to the source rate (the precision should be good to a few tenths of a per cent).

(5) If the ${ }^{252} \mathrm{Cf}$ counting rate is outside the expected range, then do a thorough check on electronics as described in Sec. 6.2 and the HINCC manual. 1

\subsection{Solution Calibration}

The PLBC is designed to assay plutonium nitrate in cylindrical bottles with an $210-\mathrm{cm}$ diam and up to a $105-\mathrm{cm}$ fill height. This corresponds to a volume of $27.5 \&$ of nitrate solution. Because there are no samples of this type at Los Alamos, we prepared three smaller cylinders of plutonium nitrate for 
calibration purposes. The solutions were contained in 2-l polyethylene bottles with a diameter of $11.5 \mathrm{~cm}$ and a fill height of $218.7 \mathrm{~cm}$. The plutonium concentrations varied from about 26 to $200 \mathrm{~g} / \mathrm{l}$. The specifications for the standards are listed in Tables II and III.

In addition to the plutonium nitrate for standards, two polyethylene bottles were filled with water for use in adding to the effective fill height of the cylinder. These water bottles moderated and scattered neutrons approximately the same as did the plutonium nitrate solution.

For the measurements, one nitrate sample and two water bottles were placed in the counter, as shown in the diagram in Fig. 7 . The plutonium

\section{TABLE I I}

PLUTONIUM NITRATE CALIBRATION STANDARDS

\begin{tabular}{|c|c|c|c|c|}
\hline $\begin{array}{l}\text { Sample } \\
\text { Number } \\
\end{array}$ & $\begin{array}{c}\text { Vol ume } \\
(\ell)\end{array}$ & $\begin{array}{c}\text { Concentration } \\
(\mathrm{g} / \mathrm{e})\end{array}$ & $\begin{array}{c}\text { Mass } \\
\text { Plutonium } \\
(\mathrm{g}) \\
\end{array}$ & $\begin{array}{c}{ }^{240} \mathrm{Pu-eff} \\
(\mathrm{g}) \\
\end{array}$ \\
\hline 1 & 1.990 & 26.51 & 52.75 & 6.124 \\
\hline 2 & 1.990 & 97.55 & 194.12 & 22.54 \\
\hline 3 & 1.990 & 198.77 & 395.55 & 45.92 \\
\hline
\end{tabular}

TABLE II I

ISOTOPICS FOR PLUTONIUM NITRATE STANDARDS

(August 4,1983 )

$\begin{array}{lc}\text { Plutonium-238 } & 0.057^{\mathrm{a}} \\ \text { Plutonium-239 } & 87.57 \\ \text { Plutonium-240 } & 11.14 \\ \text { Plutonium-241 } & 1.02 \\ \text { Plutonium-242 } & 0.208 \\ \text { Americium-241 } & 98 \mathrm{ppm}\end{array}$

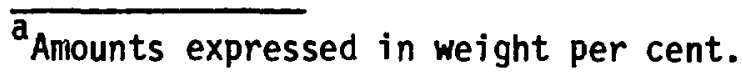




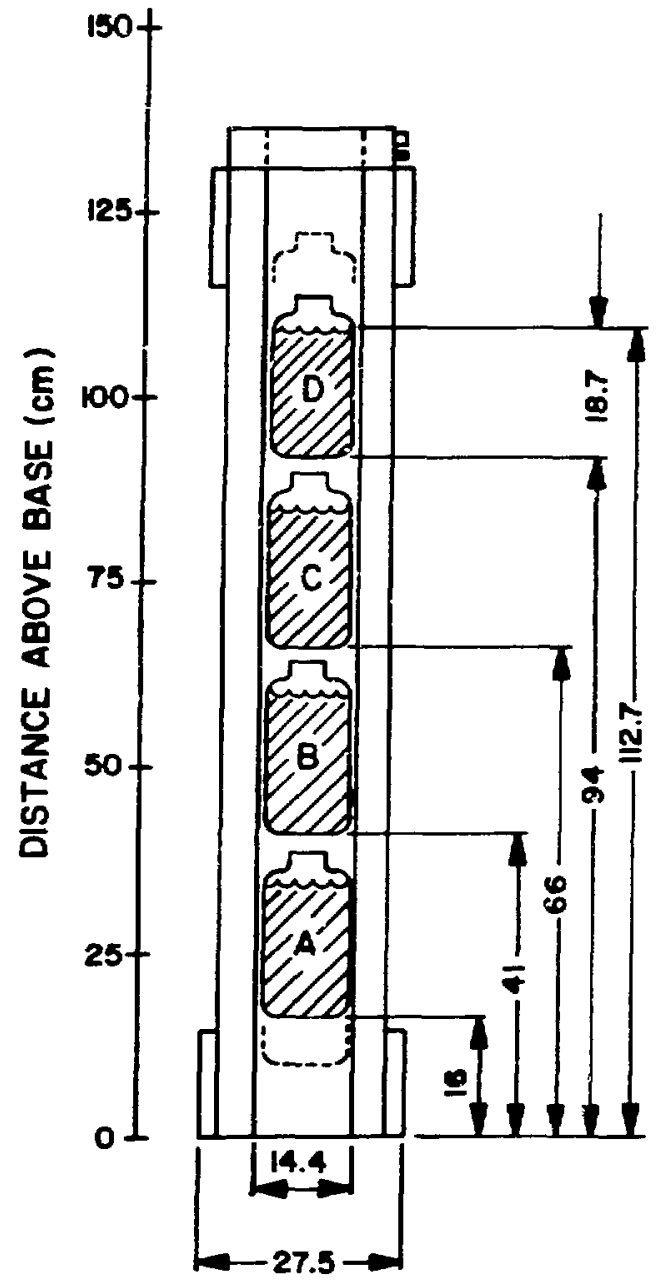

Fig. 7. Diagram of sample positions in detector for calibration using 2- $\ell$ plutonium $n i-$ trate bottles. nitrate bottle was sequentially moved through positions $A, B, C$, and $D$ to give a scan of the counter efficiency. The integral of the four positions was then used to approximate a normal-sized cylinder filled with plutonium nitrate. Both the totals rate $T$ and coincidence rate $R$ were recorded at each position.

5.2.1. Scan Profile. Each of the three concentrations was measured at positions $A-D$. When the counting rates are normalized to the average rate for the four positions, then the ratio is independent of the particular sample. Each sample was used to measure the normalized profiles $R / \bar{R}$ and $T / \bar{T}$. The results from the three concentrations were combined to give the average profiles listed in Table IV. For one of the samples, the measurement region was extended by lowering the bottle $5 \mathrm{~cm}$ below position $A$ and raising the bottle $5 \mathrm{~cm}$ above position $D$. The total sample height covered by Tabie IV is $118 \mathrm{~cm}$.

The standard deviation of the coincidence rates for the different positions is 22\%. For normal applications $(\leq 97-\mathrm{cm}$ fill), the bottom of the plutonium nitrate active zone should be positioned $16 \mathrm{~cm}$ above the bottom of the counter. There is a line on the outside of the PLBC to mark this position.

5.2.2. Calibration Data. The initial calibration data using the 2-l sample bottles are given in Tables $V$ and $V I . A{ }^{252} C f$ source (CR-5) was counted at the same time as the calibration for future normalization. At a later time, six IAEA ${ }^{252}$ Cf sources were cross-calibrated with CR-5 in the PLBC. 
POSITION SCAN PROFILES FOR $2-\ell$ PLUTONIUM NITRATE SAMPLES

Position

\begin{tabular}{|c|c|c|c|c|c|c|}
\hline Parameter & $\mathrm{A}-5 \mathrm{~cm}$ & A & B & C & $D$ & $\mathrm{D}+5 \mathrm{~cm}$ \\
\hline $\mathrm{R} / \overline{\mathrm{R}}$ & 1.026 & 1.025 & 0.973 & 0.994 & 1.008 & 1.019 \\
\hline$T / \bar{T}$ & 1.018 & 1.024 & 0.983 & 0.985 & 1.007 & 0.992 \\
\hline $\begin{array}{l}\text { Distance to } \\
\text { bottom }^{2}(\mathrm{~cm})\end{array}$ & 11.0 & 16.0 & 41.0 & 66.0 & 94.0 & 99.0 \\
\hline
\end{tabular}

aDistance corresponds to the separation between the bottom of the $2-\ell$ bottle and the bottom of the PLEC.

\section{TABLE $V$}

PLBC DATA FOR 2- $\ell$ BOTTLES AND $\mathrm{CO}_{2}$ TUBES

\begin{tabular}{|c|c|c|c|c|c|c|c|c|}
\hline Sample & Parameter & A & B & $\mathrm{C}$ & D & $E$ & Av & $\begin{array}{l}\sigma_{\mathrm{R}} \\
(\%) \\
\end{array}$ \\
\hline \multirow[t]{2}{*}{1} & $T_{\text {net }}$ & 1247 & 1180 & 1187 & 1224 & 4840 & 1210 & \\
\hline & $\mathrm{R}$ & 64.76 & 61.17 & 62.38 & 63.34 & 251.6 & 62.91 & 0.54 \\
\hline \multirow[t]{2}{*}{2} & $T_{\text {net }}$ & 4994 & 4777 & 4883 & 4941 & 19595 & 4899 & \\
\hline & $R^{n}$ & 359.9 & 345.8 & 360.3 & 356.1 & 1422 & 355.5 & 0.45 \\
\hline \multirow[t]{2}{*}{3} & $T_{\text {net }}$ & 9693 & 9295 & 9318 & 9520 & 37826 & 9457 & \\
\hline & $R^{2}$ & 605.4 & 568.2 & 577.2 & 589.8 & 2341 & 585.2 & 0.35 \\
\hline$C R-5$ & $\begin{array}{l}\mathrm{T}_{\text {net }}= \\
\mathrm{R}=\end{array}$ & $\begin{array}{l}29 \pm 40 \\
5 \pm 3 c\end{array}$ & $\begin{array}{l}\text { unts/s } \\
\text { ts/s }\end{array}$ & $\begin{array}{l}\text { source } \\
\text { on Augus }\end{array}$ & $\begin{array}{l}\text { a) Tuminum } \\
2,1983)\end{array}$ & rod & & \\
\hline
\end{tabular}


PLBC DATA FOR 2- $\ell$ BOTTLES AND Ar $+\mathrm{CH}_{4}$ TUBES

\begin{tabular}{|c|c|c|c|c|c|c|c|c|}
\hline Sample & Parameter & A & B & C & $D$ & E & Av & $\begin{array}{l}\sigma_{R} \\
(q) \\
\end{array}$ \\
\hline 3 & $T_{\text {net }}$ & 12242 & 11814 & 12027 & 12586 & 48668 & 12167 & \\
\hline & $R$ & 942.3 & 899.0 & 904.0 & 923.9 & 3669 & 917.3 & 0.50 \\
\hline
\end{tabular}

CR-5 $\quad T_{\text {net }}=7225 \pm 60$ counts $/ \mathrm{s}$ source on aluminum rod

$\mathrm{R}=725.1 \pm 5$ counts $/ \mathrm{s}$ (August 2, 1983)

The ${ }^{252} \mathrm{Cf}$ source should be counted on the end of the $38.6-\mathrm{cm}-1$ ong aluminum rod that fits on the top of the detector. This source holder is provided with the PLBC. In all cases, the nitrate bottle was counted with two water bottles.

The calibration data were obtained with two different sets of ${ }^{3} \mathrm{He}$ tubes. The original tubes in the PLBC were observed to be noisy under humid conditions, so they were replaced with an older, less efficient set of ${ }^{3} \mathrm{He}$ tubes containing a $\mathrm{CO}_{2}$ gas mixture. The data with $\mathrm{CO}_{2}$ tubes are given in Table V. The normal tubes that go with the PLBC contain an $\mathrm{Ar}+\mathrm{CH}_{4}$ gas mixture. A partial set of data using the tubes with the $\mathrm{Ar}+\mathrm{CH}_{4}$ mixture is given in Table VI. The original tubes were eventually repaired by Reuter-Stokes, the manufacturer, and the data were renormalized using CR-5. These data are given in Table VII.

One approach using the $2-\ell$ botties $(18.5 \mathrm{~cm}$ tal1) to simulate the long nitrate cylinders $(297 \mathrm{~cm})$ integrates the four separate measurement positions $(A-D)$. This technique covers the geometry of the sample very well because the four positions cover the same $97 \mathrm{~cm}$. However, crosstalk between adjacent bottles is not simulated completely. By placing $\mathrm{H}_{2} \mathrm{O}$ bottles in place of the missing portions of the nitrate cylinder, we approximats the thermalization, reflection, and absorption properties, but we have not accounted for some of the multiplication. Most of the multiplication will take place internal to the $2-\ell$ samples because of the importance of thermal neutrons. The mean free path length for thermal neutrons in $\mathrm{H}_{2} \mathrm{O}$ is $20.3 \mathrm{~cm}$, and the plutonium will absorb the neutrons before they travel very far. Thus the $18.5-\mathrm{cm}-\mathrm{tall}$ sample should appear long to the thermal neutrons that dominate the multiplication. 


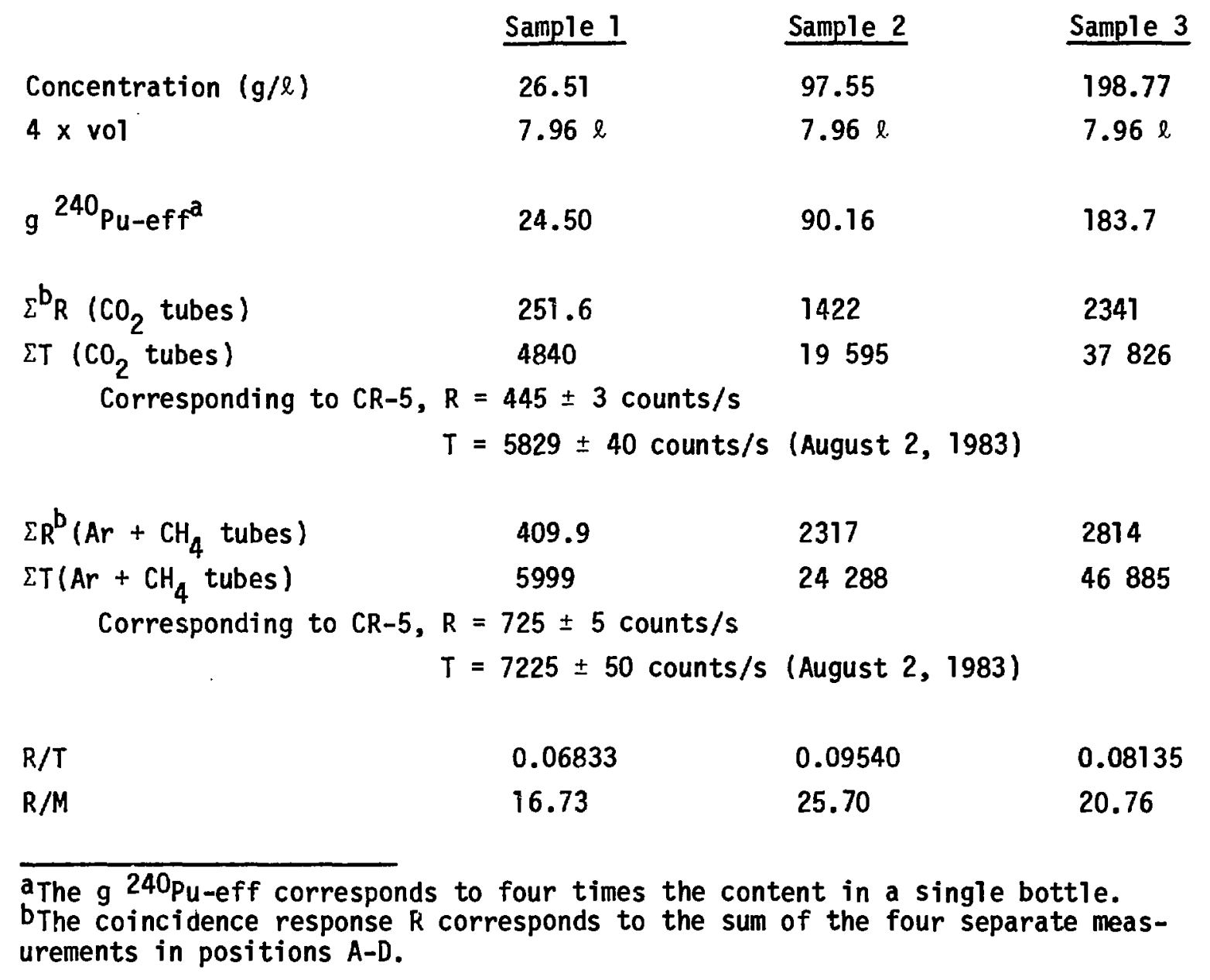

In summary, the calibration curve generated by the $2-l$ standards should slightly underpredict the absolute response from a full-length cylinder. However, the shape of the calibration function should be appropriate.

Figure 8 shows the integrai (four positions) calibration curve for the PLBC where the coincidence rates have been normalized to a CR-5 value of $R=725$ counts $/ s$ on August 2, 1983. The neutron multiplication in the sainples is apparent for the higher loadings. This curve corresponds to full cylinders with the concentration changing to give the change in $240_{\mathrm{Pu} \text {-effective. Par- }}$ tially filled cylinders with higher concentrations could be expected to give a 


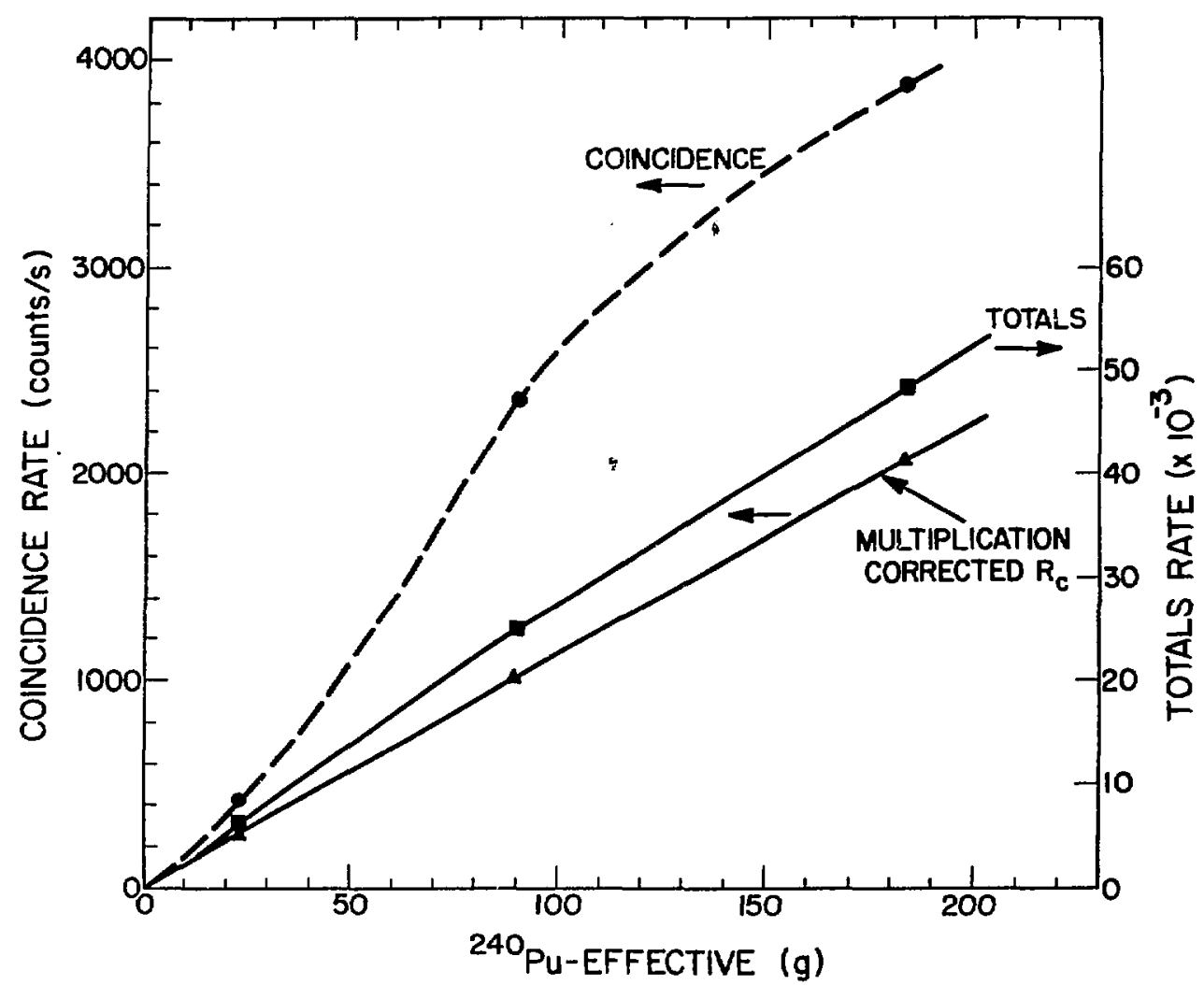

Fig. 8. Calibration curves for coincidence (top curves), totals (middle curve), and multiplication corrected coincidence rates vs plutonium loading.

response different from the curve shown in Fig. 8. However, the multiplication correction should take care of partial fills. The net weight of the samples can be used to estimate the fill height.

5.2.3. Multiplication Correction. The nonlinear behavior of the response shown in Fig. 8 is the result of neutron multiplication. This muttiplication is greater than for $\mathrm{PuO}_{2}$ samples of equivalent plutonium mass because of the neutron thermalization in the nitrate. The thermal neutrons have a much higher probability of inducing fission in the ${ }^{239} \mathrm{Pu}$ than do fast neutrons.

The amount of thermalization increases as the hydrogen fraction increases, and thus the sample with $\sim 100 \mathrm{~g} / \mathrm{l}$ plutonium has more multiplication than the sample with $\sim 200 \mathrm{~g} / \mathrm{l}$ plutonium. That is, the increase in the plutonium concentration (above $100 \mathrm{~g} / \mathrm{l}$ ) results in an increase in neutron absorption and a decrease in the hydrogen concentration, with a corresponding 
decrease in the multiplication per gram. This is clearly demonstrated in the plot of R/T vs total plutonium shown in Fig. 9. Because the isotopic mixture is the same for all samples, the higher value of $R / T$ for the $100-g / l$ material than for the $200-\mathrm{g} / \mathrm{l}$ sample indicates that the multiplication per gram is higher at the $100-\mathrm{g} / \ell$ concentration.

\section{- Graphical Correction}

$\mathrm{R} / \mathrm{g}{ }^{240} \mathrm{Pu}$ vs $\mathrm{R} / \mathrm{T}$ shown in Fig. 10. A straight line connects the three samples for each detector type, demonstrating that the samples all have the same isotopic mixture or $(\alpha, n)$ fraction. The tubes containing the $\mathrm{Ar}+\mathrm{CH}_{4}$ mixture have a higher efficiency, so their line falls above the line for the tubes with $\mathrm{CO}_{2}$. If there were no multiplication, the lines would degenerate to a point and the three samples would coincide. The $100-g / l$ sample falls above the $200-g / l$ sample on the line, demonstrating higher multiplication. Because $R$ and $R / T$ are measured, the line in Fig. 10 can be used to find $g{ }^{240} \mathrm{Pu}_{\mathrm{u}}$ independent of multiplication. This procedure will work for any concentration of the same isotopic mixture. It will also work for different isotopic

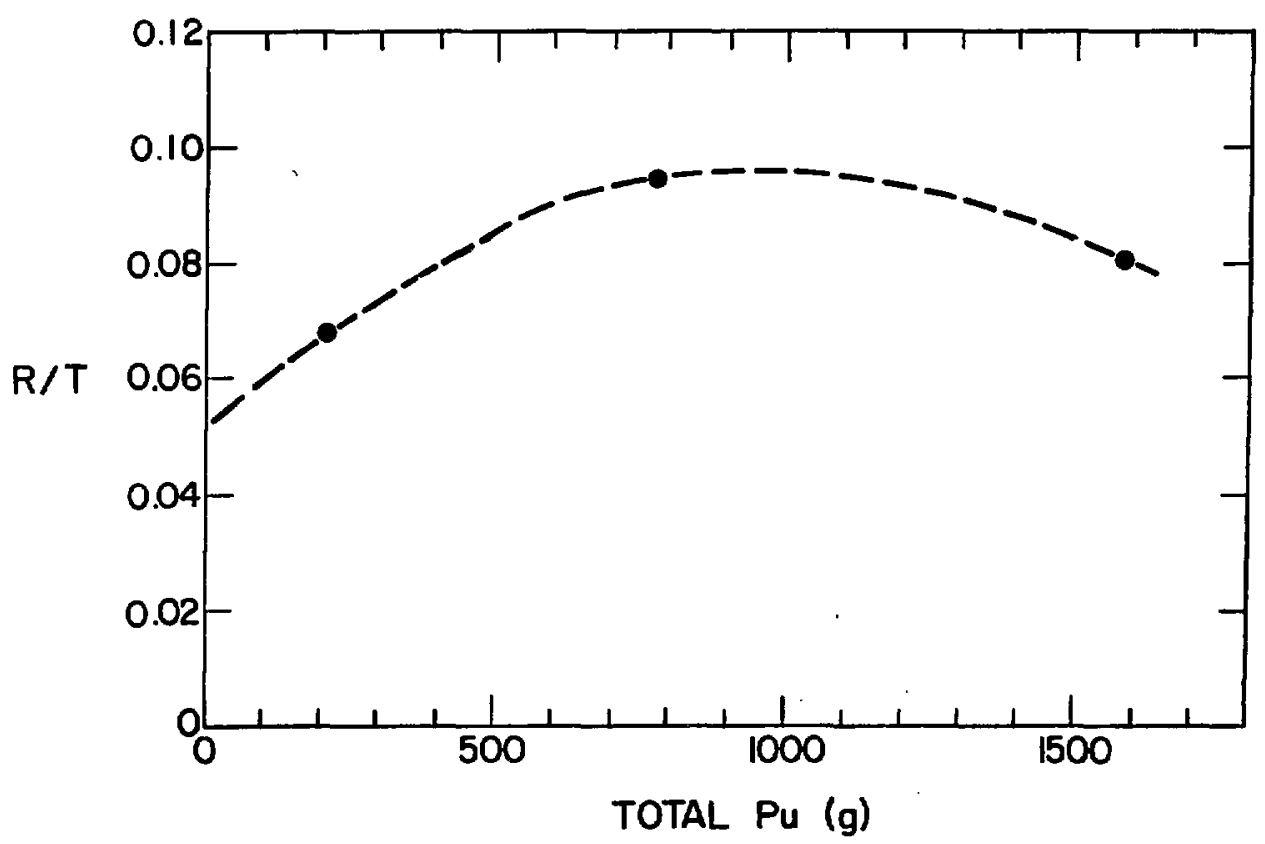

Fig. 9. The ratio of $R / T$ vs total plutonium content in four $2-\ell$ bottles. 


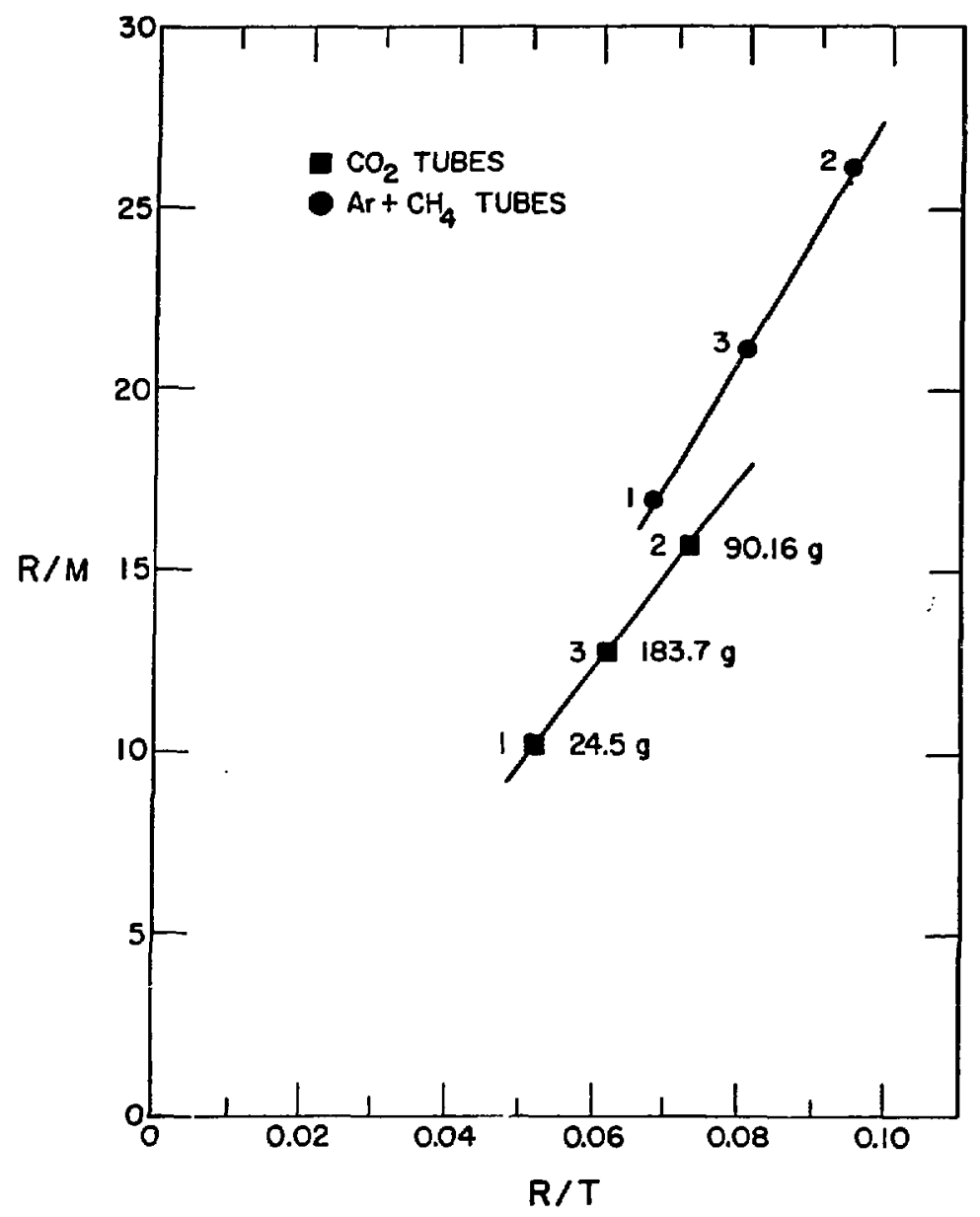

Fig. 10. Three-parameter ( $R, T, M)$ mul tiplication curves for $10 \mathrm{w}$-efficiency 3 He tubes with $\mathrm{C}_{2}$ mixture (bottom curve).

mixtures if $R / T$ is replaced by $R / T(1+\alpha)$, where $\alpha$ is the ratio of $\alpha, n$ neutrons to spontaneous fission neutrons.

- Theoretical Correction

A theoretical correction ${ }^{4}$ can be made for multiplication using the same technique as is used for the HLNCC. We used the following parameters (see Ref. 3) for the correction:

$\alpha_{0}=0.511$ (from plutonium isotopics),

$\rho_{0}=R_{0} / T_{0}=0.050$ (from Fig. 9), 


$$
\begin{aligned}
& \alpha=0.511 \text { (from isotopics), } \\
& \rho=R / T \text { (measured), } \\
& r=\frac{\rho(1+\alpha)}{\rho_{0}\left(1+\alpha_{0}\right)}=\frac{\rho}{\rho_{0}}=\frac{R / T}{0.05}, \\
& A=3(1+\alpha)=3(1.511)=4.533, \\
& B=-(3.022+4.192 \alpha+0.8689 r), \\
& C=1.192(\alpha)+0.8909=1.50, \\
& M=\frac{-B+\sqrt{B^{2}-4 A C}}{2 A}, \\
& C F=M r \quad, \text { and } \\
& R_{C}=R_{m} / C F \text {. }
\end{aligned}
$$

The correction factor CF was calculated for each of the three samples, and the corrected coincidence rate $R_{c}$ is shown at the bottom of Fig. 8. In addition, the $R / M$ values before and after correction are plotted as a function of $M$ (g 240 Pu-effective) in Fig. 1?.

The nonlinear behavior of the coincidence response is caused by multiplication. The correction technique ${ }^{4}$ currently in use by the IAEA can be used to make the response 1 inear. It is important to use the same $\rho_{0}$ value for both the calibration and assay.

Table VIII lists the calculated parameters for the three standard samples. When using these parameters for future calibrations, it will be necessary to adjust $\rho_{0}$ for any changes in the efficiency because of electronic settings. The values given in Table VIII correspond to gain settings (or high voltage) to give a $6.0-\mathrm{V}$ amplifier pulse output. The use of ${ }^{252} \mathrm{Cf}$ to check this is described in Sec. 5.2.4.

5.2.4. Californium Normalization. The calibration of the PLBC can be carried forward in time by using the ${ }^{252} \mathrm{Cf}$ neutron source normalization method. To do this, the net totals rate $T_{0}$ and coincidence rate $R_{0}$ are measured with plutonium nitrate standards at the time of calibration. At any 


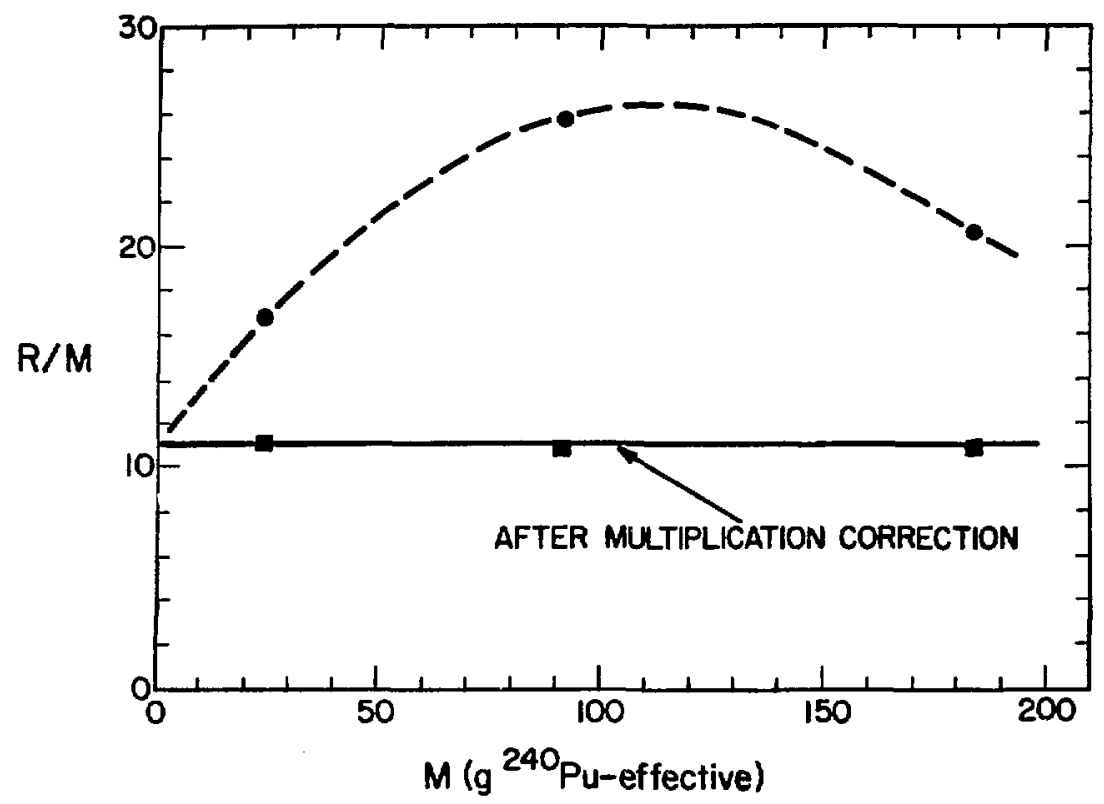

Fig. 11. Coincidence response per M (g 240pu-effective) vs $M$ before and after multiplication correction.

\section{TABLE VIII}

CALIBRATION PARAMETERS AFTER MULTIPLICATION CORRECTIONS

$$
\left(0=0.05, \alpha_{0}=0.511\right)
$$

Sample Mass ( $\mathrm{g}^{240} \mathrm{Pu}$-effective)

\begin{tabular}{lccc} 
& $24.5 \mathrm{~g}$ & $90.16 \mathrm{~g}$ & $183.7 \mathrm{~g}$ \\
\cline { 2 - 3 } $\mathrm{R}$ & 409.9 & 2317 & 3814 \\
$\rho$ & 0.06833 & 0.09540 & 0.08135 \\
$\mathrm{r}$ & 1.366 & 1.908 & 1.627 \\
$\mathrm{M}$ & 1.100 & 1.238 & 1.168 \\
$\mathrm{CF}$ & 1.503 & 2.361 & 1.900 \\
$\mathrm{R}_{C}$ & 272.7 & 981.2 & 2008 \\
$\mathrm{R}_{C} / \mathrm{M}$ & 11.13 & 10.88 & 10.93
\end{tabular}


future time, the ${ }^{252} \mathrm{Cf}$ source is remeasured and compared later decay correctlion) with the original rates. The normalizations are made as follows:

$$
R_{c}=R_{m} k_{1} \text {, }
$$

where

$$
k_{1}=\left(\frac{R_{0}}{R}\right)_{C f} ;
$$

similarly

$$
T_{c}=T_{m} k_{2},
$$

where

$$
k_{2}=\left(\frac{T_{0} \text { net }}{T \text { net }}\right)_{C f} .
$$

Note that $k_{1}$ and $k_{2}$ are not equal and in general

$$
k_{1} \simeq\left(k_{2}\right)^{2}
$$

It is not necessary to use the same ${ }^{252} \mathrm{Cf}$ source for normalization as was used for calibration as long as the second source is cross-calibrated with the

18 
original source. To avoid an error buildup in this procedure, the statistical precisions for the ${ }^{252} \mathrm{Cf}$ measurements should be good $(20.2 \%)$.

For the specific case of the PLBC calibration at Los Alamos, we measured CR-5 with

$$
\begin{aligned}
& R=725 \pm 5 \text { counts } / \mathrm{s} \\
& T=7225 \pm 50 \text { counts } / \mathrm{s}
\end{aligned}
$$

on August 2, 1983. These rates were obtained with the HV $=1500 \mathrm{~V}$ to give a $6-V$ pulse out of the amplifier, and the discriminator level was $3.0(1.5 \mathrm{~V})$. The calibration data 1 isted in Table VIII correspond to the above settings.

This calibration information can be related to the IAEA sources listed in Table IX by using the ratios to CR-5.

\section{Example Normalization Calculation}

For source IPL F-274 on June 1, 1984,

$$
\begin{aligned}
& F-274 / C R-5=0.7278 \text { (from Table IX), } \\
& R_{0}(F 274)=0.7278(725), \quad \text { (on August 2, 1983) } \\
& T_{0}(F 274)=0.7278(7225) .
\end{aligned}
$$

Updating to June 1,1984 ,

$$
\begin{aligned}
& \Delta \text { time }=0.831 y, \lambda=0.2643^{-1}, \text { and } \\
& e^{-\lambda \Delta \tau}=0.8028 \text { (cal ifornium source decay). }
\end{aligned}
$$

Calibration rates on June 1,1984 , were

$$
\begin{aligned}
& R_{0}(F 274)=0.7278(725)(0.8028)=423.6 \text { counts } / \mathrm{s}, \\
& T_{0}(F 274)=0.7278(7225)(0.8028)=4221 \text { counts } / \mathrm{s}, \\
& k_{1}=\left(\frac{R_{0}}{R}\right)_{C f}=\left(\frac{423.6}{R}\right)_{C f}, \text { and } \\
& k_{2}=\left(\frac{T_{0}}{T}\right)_{C f}=\left(\frac{4227}{T}\right)_{C f},
\end{aligned}
$$

where $R$ and $T$ are the measured rates for cal ifornium on June 1, 1984 . 
TABLE IX

CALIFORNIUM-252 SOURCE STANDARDS INTERCOMPARISON SUMMARY

\begin{tabular}{lllll}
$\begin{array}{c}\text { Source } \\
\text { Number }\end{array}$ & $\begin{array}{c}\text { Absolute Yield } \\
11 / 17 / 83 \\
(\mathrm{n} / \mathrm{s})\end{array}$ & $\begin{array}{c}\text { Relative } \\
\text { Yield }\end{array}$ & $\begin{array}{c}\sigma_{\mathrm{R}} \\
(\%)\end{array}$ & $\begin{array}{c}(11 / 17 / 83) \\
(\mu \mathrm{g})\end{array}$ \\
\cline { 2 - 3 } & $5.77 \times 10^{4}$ & 0.7278 & 0.2 & 0.0247 \\
IPL F274 & $5.33 \times 10^{4}$ & 0.6716 & 0.2 & 0.0228 \\
IPL F275 & $5.30 \times 10^{4}$ & 0.6676 & 0.2 & 0.0227 \\
IPL F276 & $5.74 \times 10^{4}$ & 0.7231 & 0.2 & 0.0245 \\
IPL F277 & $5.63 \times 10^{4}$ & 0.7097 & 0.2 & 0.0241 \\
IPL F278 & $5.20 \times 10^{4}$ & 0.6553 & 0.2 & 0.0222 \\
IPL F279 & $7.93 \times 10^{4}$ & 1.000 & 0.2 & 0.0339 \\
CR-5 & & & &
\end{tabular}

a The absolute yields were determined by intercomparison with $\mathrm{CR}-6$ that was calibrated by National Bureau of Standards with an accuracy of $\pm 1.2 \%$ on $10 / 15 / 79$.

6. MAINTENANCE

Having no moving parts, the PLBC requires little periodic mechanical maintenance. Maintenance and repair of the electronics package are the same as for the HLNCC.

6.1. Detector Body

The desiccant in the junction boxes of the detector body should be changed approximately once a year if the instrument is in a humid environment. To do this, use the following procedure:

(1) Shut off the high voltage. Remove high-voltage cable from the tube junction box and ground the high-voltage input.

(2) Remove the screws holding the lid in place. Remove the lid from the junction box. Take care not to damage the rubber gasket.

(3) Remove the desiccant holder from the undersurface of the lid and discard the old desiccant. 
(4) Replace the desiccant and reassemble the holder. (Note that the old desiccant can be rejuvenated by placing it in an oven overnight at $2150^{\circ} \mathrm{C}$ or until it regains its blue indicating color.)

(5) Redate the junction box for future reference.

\subsection{Amplifier Test Procedures}

If the initial measurements described in Sec. 5.1 indicate that one or more of the amplifier channels are out of specification, then additional tests are necessary.

The six amplifier test jacks on the instrument front pane1 allow the user to observe the analog signal from each of the six channels at the input to the discriminator circuits. The pulse-shaping amplifiers produce positive leading bipolar pulses with 0.5 - $\mu$ s integrating and differentiating time constants. The ground test jack is connected to the signal ground and is used with the signal test jack. The six amplification channels are observed independently to verify correct operation of the analog circuit. ${ }^{2}$ Proceed as follows:

(1) Connect a high-impedance oscilloscope probe to test jack 1; connect the ground probe to the ground test jack.

(2) Place the ${ }^{252} \mathrm{Cf}$ source in the PLBC and observe the oscilloscope display of the amplifier test point signal.

(3) This pulse should be bipolar with a maximum amplitude of $\sim 6 \mathrm{~V}$ and a recovery time of $4 \mu \mathrm{s}$.

(4) Repeat step 1 for amplifiers 2 and 6.

This procedure will isolate any bad preamplifier or amplifier channels.

Refer to the HLNCC maintenance manual for corrective action. If only one or two of the channels are olit, the instrument can still be used by normalizing the coincidence response to the ${ }^{252} \mathrm{Cf}$ calibration source as described in Ref. 1.

\section{SUMMARY}

The preliminary calibration performed at Los Alamos can be used to independently determine the $g{ }^{240}$ Pu-effective for the plutonium nitrate bottles measured during inspection. A more accurate calibration can be obtained after samples from selected nitrate cylinders are analyzed. 
Because the multiplication has such a strong effect on the measurement of nitrate samples, a multiplication correction should be applied to the data using the procedure from Sec. 5.2.3.

A ${ }^{252}$ Cf source should be assigned to the PLBC, and this source should be counted at the time of calibration and at each subsequent use of the detector for normalization purposes.

\section{ACKNOWLEDGMENTS}

We wish to acknowledge the assistance received from $R$. Abedin-Zadeh and D. Terrey from the IAEA in the calibration of the PLBC.

\section{REFERENCES}

1. M. S. Krick and H. O. Melllove, "The High-Level Neutron Coincidence Counter (HLNCC): Users' Manual," Los Alamos Scientific Laboratory report LA-7779-M (ISPO-53) (June 1979).

2. J. E. Swansen, P. R. Collinsworth, and M. S. Krick, "Shift-Register Coincidence Electronics System for Thermal Neutrcn Counters," Nuc]. Instrum. Methods 176 (1980).

3. M. S. Krick, "Neutron Multiplication Corrections for Passive Therma1 Neutron Weil Counters," Los Alamos Scientiric Laboratory report LA-8460-MS (ISP0-89) (Ju1y 7980).

4. N. Ensslin, J. Stewart, and J. Sapir, "Self-Multiplication Correction Factors for Neutron Coincidence Counting," Nucl. Mater. Manage. 8, 60 (i979). 